\title{
OPEN Quantum chemical insight into the effects of the local electron environment on $\mathrm{T}_{2} *$-based MRI
}

\author{
M. S. Petronek ${ }^{1,4 凶}$, J. J. St-Aubin ${ }^{1}$, C. Y. Lee ${ }^{2}$, D. R. Spitz ${ }^{1}$, E. G. Gillan ${ }^{3}$, B. G. Allen ${ }^{1,6} \&$ \\ V. A. Magnotta ${ }^{2,5,6 \bowtie}$
}

$\mathrm{T}_{2} *$ relaxation is an intrinsic magnetic resonance imaging (MRI) parameter that is sensitive to local magnetic field inhomogeneities created by the deposition of endogenous paramagnetic material (e.g. iron). Recent studies suggest that $\mathrm{T}_{2}{ }^{*}$ mapping is sensitive to iron oxidation state. In this study, we evaluate the spin state-dependence of $T_{2} *$ relaxation using $T_{2} *$ mapping. We experimentally tested this physical principle using a series of phantom experiments showing that $T_{2} *$ relaxation times are directly proportional to the spin magnetic moment of different transition metals along with their associated magnetic susceptibility. We previously showed that $\mathrm{T}_{2} *$ relaxation time can detect the oxidation of $\mathrm{Fe}^{2+}$. In this paper, we demonstrate that $\mathrm{T}_{2}$ * relaxation times are significantly longer for the diamagnetic, $\mathrm{d}^{10}$ metal $\mathrm{Ga}^{3+}$, compared to the paramagnetic, $\mathrm{d}^{5}$ metal $\mathrm{Fe}^{3+}$. We also show in a cell culture model that cells supplemented with $\mathrm{Ga}^{3+}(S=0)$ have a significantly longer relaxation time compared to cells supplemented with $\mathrm{Fe}^{3+}(\mathrm{S}=5 / 2)$. These data support the hypothesis that dipoledipole interactions between protons and electrons are driven by the strength of the electron spin magnetic moment in the surrounding environment giving rise to $\mathrm{T}_{2} *$ relaxation.

$\mathrm{T}_{2}{ }^{\star}$ mapping is a clinically accepted imaging tool for the assessment of iron overload in the heart and liver ${ }^{1-7}$. In both organs, $\mathrm{T}_{2}{ }^{*}$ relaxation times have a direct, inverse correlation with total iron content ${ }^{8-11}$. Recent studies suggest that $\mathrm{T}_{2}{ }^{*}$ relaxation times also correlate with iron oxidation state. In an ex vivo model system, the addition of a reducing agent significantly increased $\mathrm{T}_{2}{ }^{*}$ relaxation times ${ }^{12}$. Moreover, as part of an ongoing phase II clinical trial, glioblastoma patients treated with a combination of radiation, temozolomide, and pharmacological ascorbate demonstrated increased $\mathrm{T}_{2}{ }^{*}$ relaxation times following pharmacological ascorbate treatment ${ }^{13}$. In this context, the authors propose that ascorbate can act as a reducing agent facilitating the conversion of ferric $\left(\mathrm{Fe}^{3+}\right)$ to ferrous $\left(\mathrm{Fe}^{2+}\right)$ iron and that $\mathrm{T}_{2}^{*}$ relaxation time is sensitive to iron oxidation state, in addition to total iron content.

$\mathrm{T}_{1}, \mathrm{~T}_{2}$, and $\mathrm{T}_{2}{ }^{*}$ relaxation are intrinsic contrast mechanisms in MR imaging. Following the application of a radiofrequency $(\mathrm{RF})$ pulse at the resonant (i.e. Larmor) frequency, a portion of the protons will be tipped away from the Z-axis and into the XY-plane. Once the RF pulse is turned off, affected protons will begin to (1) re-align in Z-axis and (2) dephase in the XY-plane due to interactions with other protons. The time for affected proton spins to re-align in the $\mathrm{Z}$-axis is the $\mathrm{T}_{1}$ relaxation time and the time for the same protons to dephase in the $\mathrm{XY}$ plane is known as the $T_{2}$ relaxation time. $T_{1}$ and $T_{2}$ relaxation are inherent properties of the tissue and does not include local field variations. $\mathrm{T}_{2}{ }^{*}$ relaxation is the increased dephasing of proton spins in the XY-plane ${ }^{14}$ due to local magnetic field inhomogeneities from (a) intrinsic inhomogeneities associated with scanner variations and (b) deposition of endogenous or exogenous paramagnetic materials within the anatomical region of interest (e.g. iron). Protons in the presence of these magnetic field inhomogeneities dephase more rapidly resulting in the $\mathrm{T}_{2}{ }^{*}$ relaxation times being shorter than $\mathrm{T}_{2}$ relaxation times.

Transition metals can exist in a variety of oxidation states with a wide array of spin configurations. The most physiologically relevant transition metal is iron, which can exist in the ferric $\left(\mathrm{Fe}^{3+}\right)$ and ferrous $\left(\mathrm{Fe}^{2+}\right)$ state, although it may also transiently exist as $\mathrm{Fe}^{4+15-17}$. Other transition metals are also present within tissues. Manganese $(\mathrm{Mn})$ and copper $(\mathrm{Cu})$ are both present in proteins such as superoxide dismutase 1 and 2

\footnotetext{
${ }^{1}$ Department of Radiation Oncology, University of lowa, lowa City, IA, USA. ${ }^{2}$ Department of Radiology, University of lowa, lowa City, IA, USA. ${ }^{3}$ Department of Chemistry, University of lowa, lowa City, IA, USA. ${ }^{4}$ Division of Free Radical and Radiation Biology, Department of Radiation Oncology, The University of lowa Hospitals and Clinics, lowa City, IA 52242-1181, USA. ${ }^{5}$ Department of Radiology, The University of lowa Hospitals and Clinics, lowa City, IA 52242, USA. ${ }^{6}$ These authors contributed equally: B. G. Allen and V. A. Magnotta. ${ }^{\square}$ email: michael-petronek@ viowa.edu; vincent-magnotta@uiowa.edu
} 
$(\mathrm{SOD} 1=\mathrm{CuZnSOD} \text {; SOD2 }=\text { MnSOD })^{18,19}$. Typically, the $5 \mathrm{~d}$-orbitals of transition metals are degenerate in a labile state. However, when coordinated by a ligand (e.g. under physiological conditions), the d-orbitals exhibit a loss of degeneracy. The number of bound ligands and ligand bond strengths determine the associated d-orbital splitting. This loss of degeneracy gives rise to an angular momentum associated with unpaired electrons for these metals. For example, a high spin iron complex with an octahedral ligand configuration has a quantum spin (S) of $S=5 / 2$ $\left(\mathrm{Fe}^{3+}\right)$ or $2\left(\mathrm{Fe}^{2+}\right)$. Conversely, low spin iron will have $\mathrm{S}=1 / 2\left(\mathrm{Fe}^{3+}\right)$ or $0\left(\mathrm{Fe}^{2+}\right)$. Based on the number of d-orbital electrons, transition metals exhibit a wide array of quantum spins (Supplemental Table S1). The unpaired electrons thus exhibit a spin magnetic moment $\left(\mu_{s}\right)$ that is related to the number of unpaired electrons (Eq. (1)):

$$
\mu_{s}=g \sqrt{S(S+1)}
$$

where $g$ is the electronic $g$-factor $(\approx 2.002)$.

The spin magnetic moment of transition metals is directly related to their measured paramagnetic molar susceptibility $\left(\chi_{m o l}\right)$ (Eq. $\left.(2)\right)$ :

$$
\mu_{s}=\sqrt{\frac{3 k \chi_{m o l} T}{N \beta^{2}}}=2.828 \sqrt{\chi_{m o l} T},
$$

where $k=$ Boltzmann's constant, $\mathrm{N}$ is Avogadro's number, $\beta$ is the Bohr magneton, and $\mathrm{T}$ is the temperature in Kelvin (K). The unpaired electron's orbital angular momentum contribution to transition metal ion magnetic moments is usually small or negligible, in contrast to lanthanide ions where this can be a significant additional magnetic contribution. Thus, $\mu_{s}$ or $\mathrm{S}$ is often sufficient to estimate $\chi_{m o l}$ for transition metal ions.

To evaluate the relationship between the number of unpaired electrons and magnetic susceptibility through the associated magnetic moment, Eqs. (1) and (2) can be rearranged to show:

$$
\chi_{m o l}=\frac{S(S+1)}{1.99 T} .
$$

A paramagnetic compound has a non-zero electron spin and associated magnetic moment that can engage in proton-electron dipole-dipole interactions. Thus, we hypothesize that the electron spin magnetic moment has a significant impact on $\mathrm{T}_{2}{ }^{*}$ relaxation and that $\mathrm{T}_{2}{ }^{*}$ mapping is sensitive to alterations in the electronic properties of biologically relevant transition metals.

\section{Results}

$\mathrm{T}_{2}$ * relaxation times are directly proportional to magnetic susceptibility. Equation (3) indicates that $\chi_{\mathrm{mol}}$ is directly proportional to the spin quantum number associated with the number of unpaired electrons. We reviewed previously published data regarding molar susceptibility of various transition metal compounds $\left(\mathrm{Fe}^{3+}, \mathrm{Mn}^{2+}, \mathrm{Fe}^{2+}, \mathrm{Ni}^{2+}, \mathrm{Cu}^{2+}\right.$; Supplemental Table S2) and found that their relative $\chi_{\text {mol }}$ values are directly proportional to the associated $S(S+1)$ term $\left(R^{2}=0.73, r=0.98\right.$; Supplemental Fig. $\left.S 1\right)$. To test the sensitivity of $\mathrm{T}_{2}{ }^{*}$ relaxation to the electron configuration, we first measured the volumetric magnetic susceptibility $\left(\chi_{\text {vol }}\right)$ of various transition metals at an equal concentration $(1 \mathrm{M})$. We observed that $\chi_{\text {vol }}$ is linearly dependent upon the number of quantum spin $(S(S+1))$ of the transition metal $\left(R^{2}=0.98\right.$; Fig. $\left.1 A\right)$. To validate this result, we compared the known values for different metal complexes $\left(\chi_{\text {mol,exp }}\right)$ to our experimentally determined susceptibility values $\left(\chi_{\text {vol,obs }}\right)$ and found a linear relationship as anticipated $\left(R^{2}=0.99\right.$, Supplemental Fig. S2). Our experimental $\chi_{v o l}$ measures are reported in $\mathrm{ppm}$, which can be used to calculate the associated $\chi_{m o l}$ values using the following relationship (Eq. (4)):

$$
\chi_{\mathrm{mol}}=\frac{\mathrm{M}}{\rho} * \chi_{\mathrm{vol}}
$$

where $\mathrm{M}$ is the molar mass $\left(\mathrm{kg} \mathrm{mol}^{-1}\right)$ and $\rho\left(\mathrm{m}^{3} \mathrm{~kg}^{-1}\right)$.

To test if these paramagnetic metals have a similar effect on $\mathrm{T}_{2}^{*} ; \mathrm{Cu}^{2+}, \mathrm{Ni}^{2+}, \mathrm{Fe}^{2+}$, and $\mathrm{Fe}^{3+}$ were embedded in a $1 \%$ agarose gel at an equal concentration $(100 \mu \mathrm{M})$ and scanned using a $7 \mathrm{~T}$ magnet to generate $\mathrm{T}_{2}{ }^{*}$ maps (Fig. 1B). $\mathrm{T}_{2}{ }^{*}$ relaxation times were linearly dependent on the quantum spin $(\mathrm{S}(\mathrm{S}+1))$ for the examined transition metals $\left(\mathrm{R}^{2}=0.89\right.$, Fig. $\left.1 \mathrm{C}\right) . \mathrm{T}_{2}{ }^{*}$ relaxation times were also inversely proportional to the experimentally determined $\chi_{\text {vol }}$ measurements $\left(\mathrm{R}^{2}=0.89, \mathrm{r}=-0.96\right.$; Fig. $\left.1 \mathrm{D}\right)$. However, it is worth noting that the signal will be nearly fully decayed for material with very large $\chi_{v o l}$ (e.g. paramagnetic MR contrast), making the evaluation of signal changes difficult. These data suggest that $\mathrm{T}_{2}{ }^{*}$ relaxation times may be significantly affected by the electron spin magnetic moment $\left(\mu_{\mathrm{s}}\right)$ and number of unpaired electrons $(\mathrm{S})$ in the surrounding environment.

$\mathrm{T}_{2}$ * mapping detects Fenton chemistry. To determine if the oxidation of $\mathrm{Fe}^{2+}$ via Fenton chemistry reaction (Eq. (5)) is reflected in $\mathrm{T}_{2}{ }^{*}$ relaxation, $\mathrm{H}_{2} \mathrm{O}_{2}$ was incubated at room temperature and pressure with ferrous ammonium sulfate $\left(\mathrm{FAS} ; \mathrm{Fe}^{2+}\right)$.

$$
\mathrm{H}_{2} \mathrm{O}_{2}+\mathrm{Fe}^{2+} \rightarrow \mathrm{Fe}^{3+}+\mathrm{HO}^{-}+\mathrm{HO}^{\circ}
$$

Following a 15 min incubiation, the $\mathrm{H}_{2} \mathrm{O}_{2}$ concentration was $100.4 \pm 1.4 \mathrm{mM}$ as compared to $0.59 \pm 0.02 \mathrm{mM}$ with FAS (Fig. 2A). To assess the oxidation of $\mathrm{Fe}^{2+}$ by $\mathrm{H}_{2} \mathrm{O}_{2}$, each solution $\left(\mathrm{H}_{2} \mathrm{O}_{2}\right.$, FAS, and $\left.\mathrm{H}_{2} \mathrm{O}_{2}+\mathrm{FAS}\right)$ was diluted 1:15 in $5 \mathrm{mM}$ ferrozine buffer and measured using UV-Vis spectroscopy at $562 \mathrm{~nm}$ (Supplemental Fig. S3). This technique allows for the detection of a purple ferrozine- $\mathrm{Fe}^{2+}$ complex, while ferrozine- $\mathrm{Fe}^{3+}$ remains 

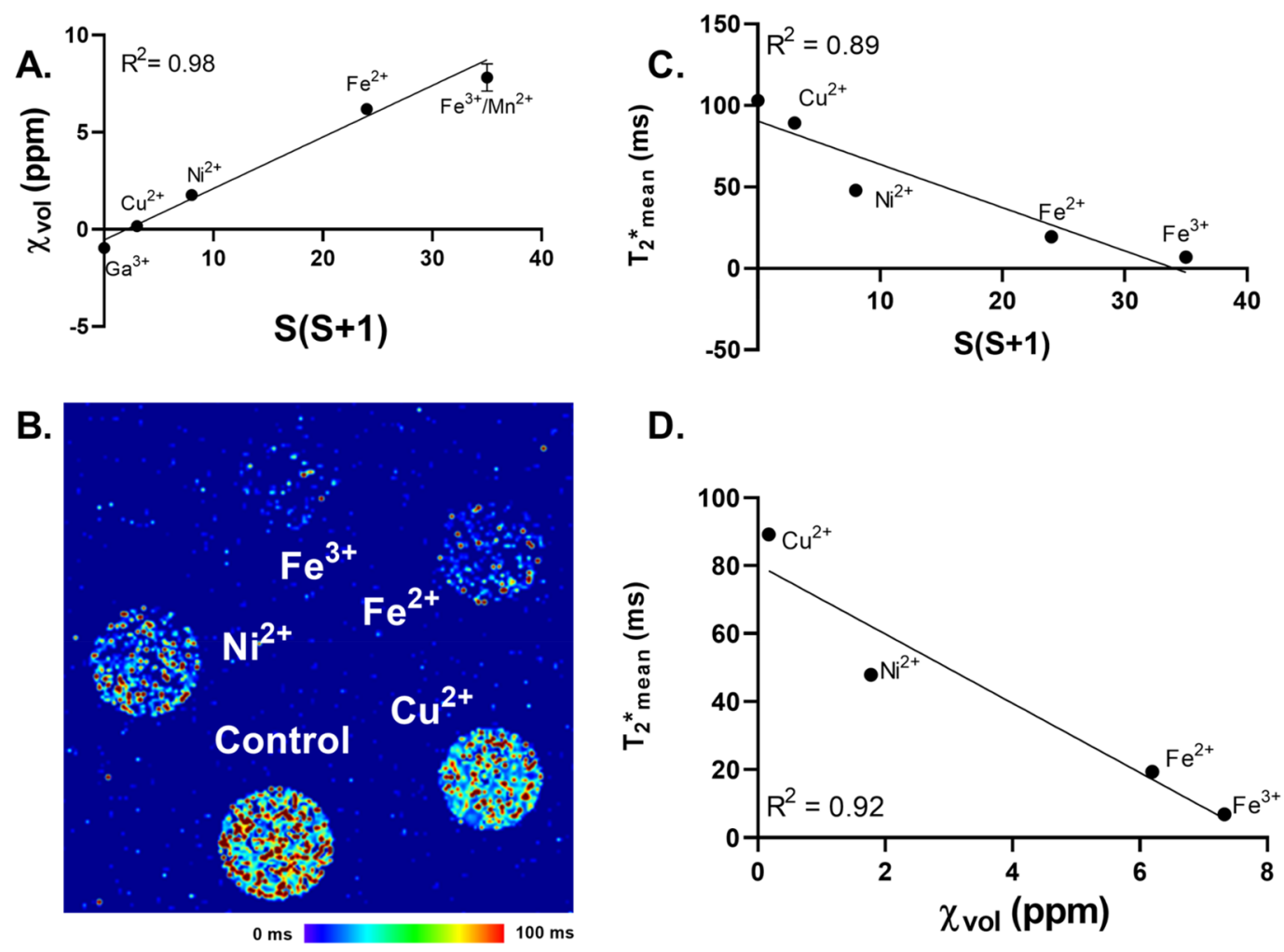

Figure 1. $\mathrm{T}_{2}{ }^{*}$ and $\chi_{\text {vol }}$ is directly proportional to the number of unpaired electrons. Volumetric magnetic susceptibility measures were taken of $1 \mathrm{M}$ concentrations of $\mathrm{Ga}\left(\mathrm{NO}_{3}\right)_{3}\left(\mathrm{Ga}^{3+}\right), \mathrm{CuSO}_{4}\left(\mathrm{Cu}^{2+}\right), \mathrm{NiCl}_{2}\left(\mathrm{Ni}^{2+}\right)$, $\left(\mathrm{NH}_{4}\right)_{2} \mathrm{Fe}\left(\mathrm{SO}_{4}\right)_{2} \cdot 6 \mathrm{H}_{2} \mathrm{O}\left(\mathrm{FAS}, \mathrm{Fe}^{2+}\right), \mathrm{Fe}\left(\mathrm{NO}_{3}\right)_{3}\left(\mathrm{Fe}^{2+}\right)$, and $\mathrm{MnSO}_{4}\left(\mathrm{Mn}^{2+}\right)$ in $4 \mathrm{~mm}$ O.D. quartz EPR tubes. Samples were prepared at room temperature $\left(25^{\circ} \mathrm{C}\right)$. (A) Linear correlation between experimentally determined volumetric magnetic susceptibility and the spin-only magnetic moment of various inorganic species. Each metal was left unchelated and diluted in double-distilled $\mathrm{H}_{2} \mathrm{O}$ at a $1 \mathrm{M}$ concentration. (B) $\mathrm{T}_{2}{ }^{*}$ map of transition metals $(100 \mu \mathrm{M})$ embedded in a $1 \%$ agarose gel and scanned using a $7 \mathrm{~T}$ scanner. (C) Linear correlation between experimentally determined $\mathrm{T}_{2}{ }^{*}$ relaxation times and the spin-only magnetic moment of various inorganic species. (D) Linear correlation between $\mathrm{T}_{2}{ }^{*}$ relaxation times and volumetric magnetic susceptibilities determined experimentally. Each experiment was done with triplicate measures.

colorless $^{20}$. Following $\mathrm{H}_{2} \mathrm{O}_{2}$ addition, $\mathrm{Fe}^{2+}$ concentration was $0.37 \pm 0.01 \mu \mathrm{M}$ compared to a final, unperturbed $\mathrm{Fe}^{2+}$ concentration of $90.0 \pm 1.2 \mu \mathrm{M}$ (Fig. 2B). Each sample $\left(\mathrm{H}_{2} \mathrm{O}_{2}\right.$, FAS, and $\mathrm{H}_{2} \mathrm{O}_{2}+\mathrm{FAS}$ ) was then diluted $1: 15 \mathrm{in} 1 \%$ agarose gel and scanned at $7 \mathrm{~T}$ to generate a $\mathrm{T}_{2}{ }^{*}$ map (Fig. $2 \mathrm{C}$ ). Quantitative analysis of each phantom revealed a mean $\mathrm{T}_{2}{ }^{*}$ relaxation time of $70.9 \pm 1.5 \mathrm{~ms}$ for the $\mathrm{H}_{2} \mathrm{O}_{2}$ sample, $54.4 \pm 0.4 \mathrm{~ms}$ for the unperturbed $\mathrm{Fe}^{2+}$ sample, and $38.4 \pm 0.1 \mathrm{~ms}$ following oxidation (Fig. 2D). These data suggest that $\mathrm{T}_{2}{ }^{\star}$ mapping can detect the chemical conversion of $\mathrm{Fe}^{2+}$ to $\mathrm{Fe}^{3+}$ via Fenton chemistry.

$\mathrm{T}_{2}$ * relaxation differentiates between $\mathrm{Ga}^{3+}$ and $\mathrm{Fe}^{3+} . \quad \mathrm{Ga}^{3+}$ is a $\mathrm{d}^{10}$ post-transition metal that is diamagnetic due to a completely full $\mathrm{d}$ orbital set with ten paired electrons $(\mathrm{S}=0)$ while $\mathrm{Fe}^{3+}$ is a highly paramagnetic $\mathrm{d}^{5}$ metal with $\mathrm{S}=5 / 2$ because of its five unpaired electrons. As expected, the $\mathrm{Ga}^{3+}$ phantom had a significantly longer $\mathrm{T}_{2}{ }^{*}$ relaxation time $(92.2 \pm 1.6 \mathrm{~ms})$ compared to $\mathrm{Fe}^{3+}(74.5 \pm 2.0 \mathrm{~ms})$ (Fig. $\left.3 \mathrm{~A}, \mathrm{~B}\right)$.

$\mathrm{Ga}^{3+}$ and $\mathrm{Fe}^{3+}$ also behave similarly in biological systems as they both bind transferrin in circulation and enter cells through transferrin-receptor mediated endocytosis ${ }^{21-23}$. Treatment of U251 glioblastoma cells with either $120 \mu \mathrm{M} \mathrm{Ga}^{3+}$ or Fe ${ }^{3+}$ for $3 \mathrm{~h}$ caused a significant increase in $\mathrm{T}_{2}{ }^{*}$ relaxation times $(152.0 \pm 1.7 \mathrm{~ms})$ in Ga ${ }^{3+}$ treated cells compared to untreated cells $(133.3 \pm 3.1 \mathrm{~ms})$ while $\mathrm{Fe}^{3+}$ resulted in a significant decrease in $\mathrm{T}_{2}^{*}$ relaxation (119.9 \pm 3.9 ms; Fig. 3C,D).

\section{Discussion and conclusions}

Several studies have showed that $\mathrm{T}_{2}{ }^{*}$ mapping is a useful tool for assessing iron concentrations in vivo. $\mathrm{T}_{2}{ }^{*}$ is widely accepted as an imaging approach to assess for iron overload in the heart and liver ${ }^{5-11}$. It has also been shown that $\mathrm{T}_{2}{ }^{*}$ is directly proportional to iron concentration in various cortical brain regions ${ }^{24}$. However, more recent studies have suggested that $\mathrm{T}^{*}$ relaxation can detect tissue iron-oxidation state ${ }^{12,13}$. We believe this is because electron contributions from the local environment are driving changes in $\mathrm{T}_{2}{ }^{*}$ due to the different $\mathrm{d}$ orbital valence configurations of $\mathrm{Fe}^{3+}\left(\mathrm{d}^{5}\right)$ and $\mathrm{Fe}^{2+}\left(\mathrm{d}^{4}\right)$. In an ex vivo model, human cadaveric brain tissue was exposed to a reductant to convert $\mathrm{Fe}^{3+}$ to $\mathrm{Fe}^{2+}$ or iron extraction to reduce the iron content of the tissue ${ }^{12}$. In both conditions, $\mathrm{T}_{2}{ }^{*}$ was increased further supporting the iron concentration dependence (iron extraction) and 

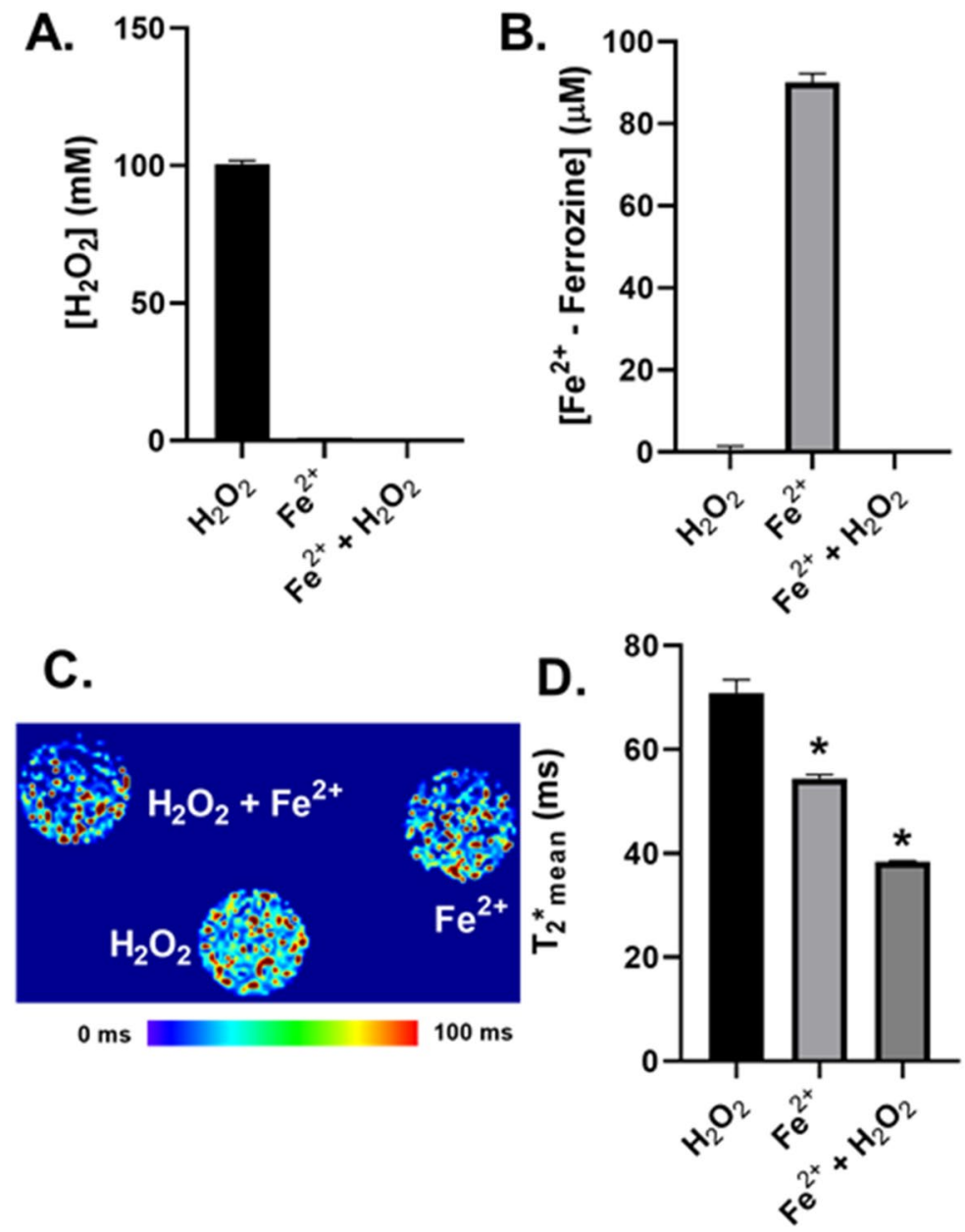

Figure 2. $\mathrm{T}_{2}{ }^{*}$ mapping detects Fenton chemistry. (A) Measurement of $\mathrm{H}_{2} \mathrm{O}_{2}$ using UV-Vis spectroscopy (240 nm; $\varepsilon=46.3 \mathrm{~mol}^{-1} \mathrm{~cm}^{-1} ; 1 \mathrm{~cm}$ pathlength) following $15 \mathrm{~min}$ incubation of $1.5 \mathrm{mM} \mathrm{FAS}\left(\left(\mathrm{NH}_{4}\right)_{2} \mathrm{Fe}\left(\mathrm{SO}_{4}\right)_{2}\right.$ $6 \mathrm{H}_{2} \mathrm{O}$ ) with $100 \mathrm{mM} \mathrm{H}_{2} \mathrm{O}_{2}$ for $15 \mathrm{~min}$ in double-distilled $\mathrm{H}_{2} \mathrm{O}$. (B) Measurement of $\mathrm{Fe}^{2+}$ following 1:15 dilution in $5 \mathrm{mM}$ ferrozine using UV-Vis spectroscopy (562 nm; $\varepsilon=27,900 \mathrm{~mol}^{-1} \mathrm{~cm}^{-1} ; 1 \mathrm{~cm}$ pathlength). (C) Representative $\mathrm{T}_{2}{ }^{*}$ map of 1:15 dilution in 1\% agarose gel. (D) Mean $\mathrm{T}_{2}{ }^{*}$ relaxation times quantified using Slicer3D software by generation a $1 \mathrm{~mm}$ ROI for each phantom and calculating the mean $\mathrm{T}_{2}^{*}$ relaxation time using the data quantification package within the software. Error bars represent SD of $n=3$ biological replicates. Statistical analysis was performed using a one-way ANOVA test with statistical significance defined as a false positivity rate less than $5 \%\left({ }^{*} p<0.05\right)$.

spin-dependence (iron reduction) theories. In a study reporting the preliminary results of a phase II trial for glioblastoma patients treated with pharmacological ascorbate, a small cohort of patients showed a significant increase in $\mathrm{T}_{2}{ }^{*}$ relaxation times $4 \mathrm{~h}$ after an $87.5 \mathrm{~g}$ infusion of ascorbate ${ }^{13}$. Ascorbate (vitamin $\mathrm{C}$ ) is a one-electron reducing agent that readily converts $\mathrm{Fe}^{3+}$ to $\mathrm{Fe}^{2+}$ and can kill cancer cells in an iron-dependent mechanism ${ }^{25-27}$. This study also showed that $\mathrm{Fe}^{3+}$ has a much greater concentration-dependent effect on $\mathrm{T}_{2}^{*}$ relaxation than $\mathrm{Fe}^{2+}$, although $\mathrm{Fe}^{2+}$ still decreased $\mathrm{T}_{2}{ }^{* 13}$. Taken together, this suggests that $\mathrm{T}_{2}{ }^{*}$ relaxation is dependent on both the concentration and spin-configuration of the paramagnetic metal being considered.

In this study, we show that $\mathrm{T}_{2}{ }^{*}$ relaxation times can detect transition metals that have varying electron spin contributions $\left(\mu_{\mathrm{s}}\right)$ and are linearly proportional to their associated magnetic susceptibility $\left(\chi_{\text {vol }}\right)$. We show that $\mathrm{T}_{2}{ }^{*}$ relaxation times are sensitive to $\mathrm{Fe}^{2+}$ oxidation and able to detect Fenton chemistry reactions. Reactions with $\mathrm{H}_{2} \mathrm{O}_{2}$ are thought to be a major contributor to Fe-mediated oxidative damage in cells ${ }^{17,28}$. Fenton chemistry is a critical oxidation step following the radiolysis of water and can lead to ionizing radiation induced DNA damage ${ }^{28-30}$. Similar to iron, copper, manganese, and nickel are also able to undergo Fenton-type reactions leading to DNA damage ${ }^{31-34}$. Therefore, being able to readily detect alterations in metal oxidation state may provide significant information regarding the biochemical processes that are central to metal catalyzed pathologic processes and therapeutic response (e.g. radiotherapy) We also demonstrate that $\mathrm{T}_{2}{ }^{*}$ mapping is able to differentiate between diamagnetic $\left(\mathrm{d}^{10} ; \mathrm{S}=0\right) \mathrm{Ga}^{3+}$ and paramagnetic $\left(\mathrm{d}^{5} ; \mathrm{S}=5 / 2\right) \mathrm{Fe}^{3+}$ metals as the high magnetic susceptibility of $\mathrm{Fe}^{3+}$ has a significant shortening of the $\mathrm{T}_{2}{ }^{*}$ relaxation time compared to $\mathrm{Ga}^{3+}$. We validated this effect in a relevant, controlled, in vitro model system that controlled for several important variables including: (1) metal concentration, (2) metal oxidation state, (3) cellular uptake. U251 glioblastoma cells were treated for 

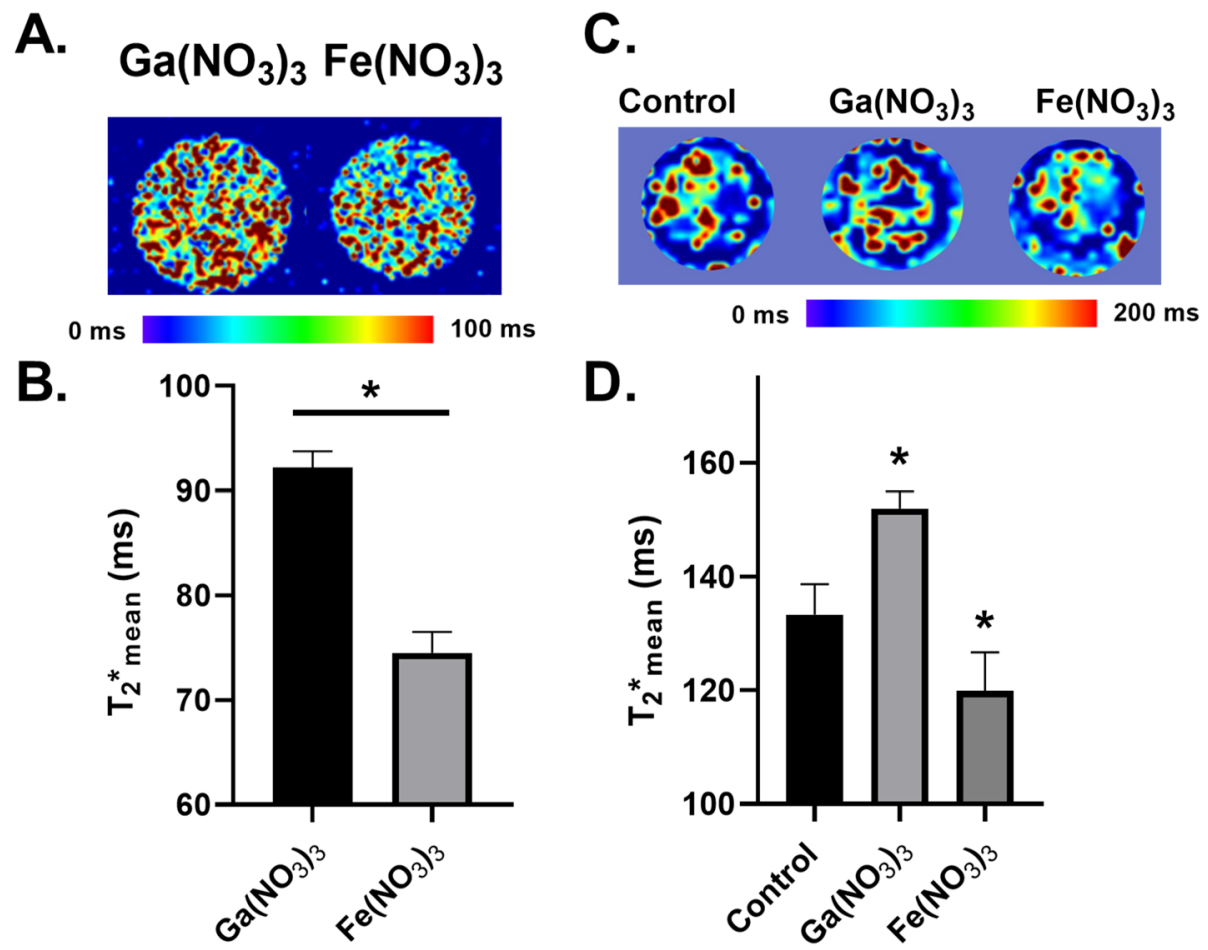

Figure 3. $\mathrm{T}^{\star}{ }^{\star}$ relaxation differentiates between $\mathrm{Ga}^{3+}$ and $\mathrm{Fe}^{3+}$. (A) $100 \mu \mathrm{M} \mathrm{Ga}\left(\mathrm{NO}_{3}\right)_{3}$ and $\mathrm{Fe}\left(\mathrm{NO}_{3}\right)_{3}$ solutions embedded in a $1 \%$ agarose gel in $4 \mathrm{~mm}$ O.D. quartz EPR tubes and scanned using a $7 \mathrm{~T}$ magnet to generate $\mathrm{T}_{2}{ }^{*}$ maps. (B) Mean $\mathrm{T}_{2}{ }^{*}$ relaxation times quantified using Slicer3D software by generating a $1 \mathrm{~mm}$ ROI for each phantom and calculating the mean $\mathrm{T}_{2}^{*}$ relaxation time using the data quantification package within the software. ${ }^{*} \mathrm{p}<0.05$ using a paired t-test. Error bars represent SEM of three replicates. (C) Representative $\mathrm{T}_{2}{ }^{*}$ map of $\mathrm{U} 251$ glioblastoma cell pellets following a $3 \mathrm{~h}$ treatment of $120 \mu \mathrm{M} \mathrm{Ga}\left(\mathrm{NO}_{3}\right)_{3}$ or $\mathrm{Fe}\left(\mathrm{NO}_{3}\right)_{3}$. (D) Mean $\mathrm{T}_{2}^{*}$ relaxation times quantified using Slicer3D software by generating a $1 \mathrm{~mm}$ ROI for each phantom and calculating the mean $\mathrm{T}_{2}{ }^{*}$ relaxation time using the data quantification package within the software. Error bars represent $\mathrm{SD}$ of $\mathrm{n}=3$ biological replicates. ${ }^{*} \mathrm{p}<0.05$ using a one-way ANOVA test.

$3 \mathrm{~h}$ with identical concentrations of either $\mathrm{Ga}^{3+}$ or $\mathrm{Fe}^{3+}(120 \mu \mathrm{M}) \cdot \mathrm{Ga}^{3+}$ and $\mathrm{Fe}^{3+}$ are both taken into cells via transferrin-receptor mediated endocytosis to control for metal uptake ${ }^{23}$. Therefore, by supplementing cells with two metals where the only notable variable is the electron spin contribution, we show that the addition of a diamagnetic metal $\left(\mathrm{Ga}^{3+}\right)$ increases $\mathrm{T}_{2}{ }^{*}$ relaxation times while the paramagnetic $\mathrm{Fe}^{3+}$ decreases $\mathrm{T}_{2}{ }^{*}$ relaxation times. This suggests that $\mathrm{T}_{2}{ }^{*}$ relaxation may be useful in detecting diamagnetic/paramagnetic shifts in cells or tissues (e.g. influx/efflux of $\mathrm{O}_{2}$ to detect hypoxia).

In conclusion, we provide a revised understanding that changes in $\mathrm{T}_{2}{ }^{\star}$ relaxation times are being altered by proton-electron dipole-dipole interactions. This novel interpretation may allow investigators and clinicians to utilize $\mathrm{T}_{2}{ }^{*}$ mapping to probe not only metal concentrations, but also, metal spin states. This understanding may be employed to develop new, non-invasive biomarkers to better understand human pathology, therapeutic response, and drug delivery by probing electron motion and metal metabolic changes in vivo.

\section{Materials and methods}

Magnetic susceptibility measures. Magnetic susceptibility measurements were performed by dissolving the desired metal to a concentration of $1 \mathrm{M}$ in double-distilled $\mathrm{H}_{2} \mathrm{O}$. Metals used in this study are provided in supplemental information (Supplemental Table S1). The metal solution was then put in a $4 \mathrm{~mm}$ O.D. Wilmadquartz EPR tube (4 mm O.D.; Wilmad-LabGlass, Vineland, NJ, 707-SQ-250 M), sealed with parafilm, and measured at room temperature using a Johnson-Matthey MSB Evans magnetic susceptibility balance. Measurements were done in comparison to a water blank.

MRI studies. Phantoms were generated by dissolving the desired metal in double-distilled $\mathrm{H}_{2} \mathrm{O}$ to get an initial concentration of $1.5 \mathrm{mM}$. Appropriate metals were then diluted 1:15 in 1\% agarose gel (Seaplaque low gelling temperature agarose; Sigma-Aldrich, A9414) and allowed to solidify in EPR tubes. Images were collected on a 7T GE MR901 small animal scanner, a part of the Small Animal Imaging Core at the University of Iowa. $\mathrm{T}_{2}{ }^{*}$ weighted images were collected using a gradient echo sequence $(\mathrm{TR}=10 \mathrm{~ms}$, $\mathrm{TE}=2.2,8.2,14.2$, and $20.2 \mathrm{~ms}$, $256 \times 256$ resolution, 2 signal averages). A B0 shimming routine was performed to mitigate the effect of macroscopic filed inhomogeneity on $\mathrm{T}_{2}{ }^{*}$ measurements. The echo time (TE) is the time between the radiofrequency pulse and the sampling of the MRI signal, the repetition time (TR) is the time between two repeated pulse cycles, 
and $\mathrm{B} 0$ is the main external magnetic field strength (7T). $\mathrm{T}_{2}{ }^{*}$ maps were generated using a combination of 4 echo times collected and fitting each voxel to a mono-exponential curve using in-house python code. Images were imported to Slicer3D software where regions of interest (ROIs) were delineated and mean $\mathrm{T}_{2}{ }^{*}$ values were calculated using the label statistics tool within Slicer3 $\mathrm{D}^{35}$.

Ultraviolet-visible light spectroscopy. Ultraviolet-visible light (UV-Vis) spectroscopic measurements were performed using a Beckman DU600 spectrophotometer. Samples were diluted to appropriate concentrations in double-distilled $\mathrm{H}_{2} \mathrm{O}$ and placed in a $1 \mathrm{~cm}$ cuvette. $\mathrm{Fe}^{2+}$-ferrozine complex formation being measured using a 400-800 nm wavelength scan and $\mathrm{H}_{2} \mathrm{O}_{2}$ was monitored using the absorbance at $240 \mathrm{~nm}$. Fe $\mathrm{e}^{2+}$-ferrozine and $\mathrm{H}_{2} \mathrm{O}_{2}$ concentrations were calculated using Beer's Law using the absorbance at $562 \mathrm{~nm}\left(\varepsilon_{562}=27,900 \mathrm{~mol}^{-1} \mathrm{~cm}^{-1}\right)$ and $240 \mathrm{~nm}\left(\varepsilon_{240}=46.3 \mathrm{~mol}^{-1} \mathrm{~cm}^{-1}\right)$, respectively.

Cell cultures. U251 glioma cells were cultured in DMEM-F12 media (15\% FBS, $1 \%$ penicillin-strep, $1 \% \mathrm{Na}$ pyruvate, $1.5 \%$ HEPES, $0.1 \%$ insulin, and $0.02 \%$ fibroblast growth factor). Cells were plated in $100 \mathrm{~mm}^{2}$ dishes and grown to $70-80 \%$ confluence at $21 \% \mathrm{O}_{2}$. Cells were either left untreated or supplemented with $120 \mu \mathrm{M} \mathrm{Ga}$ $\left(\mathrm{NO}_{3}\right)_{3}$ or $\mathrm{Fe}\left(\mathrm{NO}_{3}\right)_{3}$ for $3 \mathrm{~h}$ at $21 \% \mathrm{O}_{2}$. Cells were trypsinized and harvested by spinning at $1200 \mathrm{RPM}$ for $5 \mathrm{~min}$. Supernatant media was aspirated and cells were resuspended in $250 \mu \mathrm{L}$ DPBS. Cells were then placed in the appropriate well of a PCR plate embedded in 1\% agarose gel. Cells were allowed to collect at the bottom of the well to form a dense pellet for approximately $30 \mathrm{~min}$. Following pellet formation, the entire phantom containing all groups was scanned in the MR901 using a $6.0 \mathrm{~cm}$ FOV while all other parameters for the multi-echo gradient echo sequence was the same as used for the phantom study.

Received: 20 July 2021; Accepted: 8 October 2021

Published online: 21 October 2021

\section{References}

1. Pepe, A. et al. Detection of myocardial iron overload with magnetic resonance by native $\mathrm{T} 1$ and $\mathrm{T} 2{ }^{\star}$ mapping using a segmental approach. Eur. Heart J. Cardiovasc. Imaging. https://doi.org/10.1093/ehjci/jez111.007 (2019).

2. Anderson, L. et al. Cardiovascular T2-star $\left(\mathrm{T} 2^{\star}\right)$ magnetic resonance for the early diagnosis of myocardial iron overload. Eur. Heart J. Cardiovasc. Imaging 22, 2171-2179 (2001).

3. Henninger, B. et al. Evaluation of MR imaging with $\mathrm{T} 1$ and $\mathrm{T} 2{ }^{*}$ mapping for the determination of hepatic iron overload. Eur. Radiol. 22, 2478-2486 (2012).

4. Positano, V. et al. Improved $\mathrm{T} 2^{\star}$ assessment in liver iron overload by magnetic resonance imaging. Magn. Reson. Imaging 27, 188-197 (2009).

5. Anderson, L. J. et al. Myocardial iron clearance during reversal of siderotic cardiomyopathy with intravenous desferrioxamine: A prospective study using $\mathrm{T}^{\star}$ cardiovascular magnetic resonance. Br. J. Haematol. 127, 348-355 (2004).

6. Carpenter, J.-P. et al. On T2* magnetic resonance and cardiac iron. Circulation 123, 1519-1528 (2011).

7. Henninger, B., Alustiza, J., Garbowski, M. \& Gandon, Y. Practical guide to quantification of hepatic iron with MRI. Eur. Radiol. 30, 383-393 (2020).

8. St. Pierre, T. G. et al. Noninvasive measurement and imaging of liver iron concentrations using proton magnetic resonance. Blood 105, 855-861 (2005)

9. Wood, J. C. et al. MRI R2 and R2* mapping accurately estimates hepatic iron concentration in transfusion-dependent thalassemia and sickle cell disease patients. Blood 106, 1460-1465 (2005).

10. Ghugre, N. R. et al. MRI detects myocardial iron in the human heart. Magn. Reson. Med. 56, 681-686 (2006).

11. Wood, J. C. Magnetic resonance imaging measurement of iron overload. Curr. Opin. Hematol. 14, 183-190 (2007).

12. Birkl, C. et al. The influence of iron oxidation state on quantitative MRI parameters in post mortem human brain. Neuroimage 220, 117080 (2020).

13. Cushing, C. M. et al. Magnetic resonance imaging (MRI) of pharmacological ascorbate-induced iron redox state as a biomarker in subjects undergoing radio-chemotherapy. Redox Biol. 38, 101804 (2021).

14. Chavhan, G. B., Babyn, P. S., Thomas, B., Shroff, M. M. \& Haacke, E. M. Principles, techniques, and applications of T2*-based MR imaging and its special applications. Radiographics 29, 1433-1449 (2009).

15. Goldman, D. W., Breyer, R. J., Yeh, D., Brockner-Ryan, B. A. \& Alayash, A. I. Acellular hemoglobin-mediated oxidative stress toward endothelium: A role for ferryl iron. Am. J. Physiol.-Heart Circ. Physiol. 275, H1046-H1053 (1998).

16. Breuer, W., Shvartsman, M. \& Cabantchik, Z. I. Intracellular labile iron. Int. J. Biochem. Cell Biol. 40, 350-354 (2008).

17. Kruszewski, M. Labile iron pool: The main determinant of cellular response to oxidative stress. Mutat. Res./Fund. Mol. Mech. Mutagen. 531, 81-92 (2003).

18. Rakhit, R. \& Chakrabartty, A. Structure, folding, and misfolding of $\mathrm{Cu}, \mathrm{Zn}$ superoxide dismutase in amyotrophic lateral sclerosis. Biochim. Biophys. Acta 1762, 1025-1037 (2006).

19. Culotta, V. C., Yang, M. \& O'Halloran, T. V. Activation of superoxide dismutases: Putting the metal to the pedal. Biochim. Biophys. Acta 1763, 747-758 (2006).

20. Stookey, L. Ferrozine-A new spectrophotometric reagent for iron. Anal. Chem. 42, 781 (1970).

21. Chitambar, C. \& Narasimhan, J. Targeting iron-dependent DNA synthesis with gallium and transferrin-gallium. Pathobiology 59, 3-10 (1991).

22. Behr, S. C. et al. Targeting iron metabolism in high-grade glioma with 68Ga-citrate PET/MR. JCI Insight 3, e93999 (2018).

23. Chikh, Z., Ha-Duong, N.-T., Miquel, G. \& El Hage Chahine, J.-M. Gallium uptake by transferrin and interaction with receptor 1. J. Biol. Inorg. Chem. 12, 90-100 (2007).

24. Langkammer, C. et al. Quantitative MR imaging of brain iron: A postmortem validation study. Radiology 257, 455-462 (2010).

25. Buettner, G. R. \& Jurkiewicz, B. A. Catalytic metals, ascorbate and free radicals: Combinations to avoid. Radiat. Res. 145, 532-541 (1996).

26. Schoenfeld, J. D. et al. O2- and H2O2-mediated disruption of Fe metabolism causes the differential susceptibility of NSCLC and GBM cancer cells to pharmacological ascorbate. Cancer Cell 31, 487-500.e8 (2017).

27. Schoenfeld, J. D. et al. Redox active metals and $\mathrm{H} 2 \mathrm{O} 2$ mediate the increased efficacy of pharmacological ascorbate in combination with gemcitabine or radiation in pre-clinical sarcoma models. Redox Biol. 14, 417-422 (2018). 
28. Wardman, P. \& Candeias, L. P. Fenton chemistry: An introduction. Radiat. Res. 145, 523-531 (1996).

29. Frelon, S., Douki, T., Favier, A. \& Cadet, J. Comparative study of base damage induced by gamma radiation and Fenton reaction in isolated DNA. J. Chem. Soc. https://doi.org/10.1039/b207532f (2002).

30. Ambroz, H., Bradshaw, T., Kemp, T., Kornacka, E. \& Przybytniak, G. Role of iron ions in damage to DNA: Influence of ionising radiation, UV light and H2O2. J. Photochem. Photobiol. A 142, 9-18 (2001).

31. Pham, A. N., Xing, G., Miller, C. J. \& Waite, T. D. Fenton-like copper redox chemistry revisited: Hydrogen peroxide and superoxide mediation of copper-catalyzed oxidant production. J. Catal. 301, 54-64 (2013).

32. Watts, R. J., Judith, S., Loge, F. J. \& Teel, A. L. Oxidative and reductive pathways in manganese-catalyzed Fenton's reactions. J. Environ. Eng. 131, 158-164 (2005).

33. Lloyd, D. R. \& Phillips, D. H. Oxidative DNA damage mediated by copper(II), iron(II) and nickel(II) Fenton reactions: Evidence for site-specific mechanisms in the formation of double-strand breaks, 8-hydroxydeoxyguanosine and putative intrastrand crosslinks. Mutat. Res./Fund. Mol. Mech. Mutagenesis 424, 23-36 (1999).

34. Chiu, S., Xue, L., Friedman, L. \& Oleinick, N. Copper ion-mediated sensitization of nuclear matrix attachment sites to ionizing radiation. Biochemistry 32, 6214-6219 (1993).

35. Fedorov, A. et al. 3D Slicer as an image computing platform for the quantitative imaging network. Magn. Reson. Imaging 30, 1323-1341 (2012).

\section{Acknowledgements}

The content is solely the responsibility of the authors and does not represent the views of the National Institutes of Health.

\section{Author contributions}

M.P. wrote the main manuscript text, V.M., B.A., and J.S. reviewed prepared Figs. 1, 2 and 3, and all authors reviewed the manuscript.

\section{Funding}

This work was supported by NIH Grants T32 CA078586, P01 CA217797, P01 CA244091, R01 CA169046, R21 CA256301, and the Gateway for Cancer Research Grant G-17-1500. Core facilities were supported in part by the Carver College of Medicine and the Holden Comprehensive Cancer Center, NIH P30 CA086862.

\section{Competing interests}

The authors declare no competing interests.

\section{Additional information}

Supplementary Information The online version contains supplementary material available at https://doi.org/ 10.1038/s41598-021-00305-7.

Correspondence and requests for materials should be addressed to M.S.P. or V.A.M.

Reprints and permissions information is available at www.nature.com/reprints.

Publisher's note Springer Nature remains neutral with regard to jurisdictional claims in published maps and institutional affiliations.

(c) (1) Open Access This article is licensed under a Creative Commons Attribution 4.0 International (c) License, which permits use, sharing, adaptation, distribution and reproduction in any medium or format, as long as you give appropriate credit to the original author(s) and the source, provide a link to the Creative Commons licence, and indicate if changes were made. The images or other third party material in this article are included in the article's Creative Commons licence, unless indicated otherwise in a credit line to the material. If material is not included in the article's Creative Commons licence and your intended use is not permitted by statutory regulation or exceeds the permitted use, you will need to obtain permission directly from the copyright holder. To view a copy of this licence, visit http://creativecommons.org/licenses/by/4.0/.

This is a U.S. Government work and not under copyright protection in the US; foreign copyright protection may apply 2021 